\title{
Preparation and Microstructure Analysis of Fly Ash Geopolymer at Ambient Temperature
}

\author{
Qingwei Sun ${ }^{1,2^{*}}$ and Han $\mathrm{Zhu}^{1}$ \\ ${ }^{1}$ School of Civil Engineering, Tianjin University, Tianjin, China \\ ${ }^{2}$ College of Civil Engineering and Architecture, Liaoning Technical University, \\ Fuxin, Liaoning Province, China \\ 15386950@qq.com
}

\begin{abstract}
A high-strength geopolymer was prepared with fly ash as a raw material by mixing $25 \%$ slag and $15 \%$ cement at an ambient temperature. The influence law of water glass modulus and alkali activator dosage on geopolymer strength at an ambient temperature was systematically investigated. Results indicated that an alkali activator dosage of $7 \%$ to $8 \%$ and a sodium silicate modulus of 1.4 to 1.6 are optimal ranges to increase geopolymer strength. In addition, the microstructure of fly ash geopolymer was observed through scanning electron microscopy, X-ray diffraction, and mercury intrusion porosimetry. The relation between the microstructure and mechanical properties of the material was revealed.
\end{abstract}

Keywords: Fly ash; Geopolymer; Curing; Compressive strength; Microstructure

\section{Introduction}

Geopolymer as a new type of cementitious material has elicited an increasing amount of attention from engineers and researchers recently. Geopolymer was developed and named by the French scientist Davidovits[1]. Geopolymers not only possess excellent mechanical properties and durability but also discharge a small amount of $\mathrm{CO}_{2}$ during the preparation process; the discharged amount is only $1 / 10$ to $1 / 5$ of that discharged by cement. In addition, the toxic gas emission is almost zero, and the power consumption in the production of geopolymers is only $1 / 6$ to $1 / 4$ that of cement. Geopolymers also consume large amounts of fly ash, blast furnace slag, and other industrial waste. This waste consumption is beneficial for energy conservation and environmental protection[2-6].

The traditional preparation of geopolymers requires heat curing to obtain good performance[7-9]. This method not only consumes large amounts of energy but is also unsuitable for on-site construction operations. This condition limits the practical application of geopolymers. Thus, many scholars have conducted many active investigations on the preparation of geopolymers at ambient temperatures. Valuable results have been obtained. Somna[10] and Temuujin[11] prepared geopolymers with $28 \mathrm{~d}$ compressive strengths of 23 and $45 \mathrm{MPa}$, respectively, by grinding the raw materials and increasing the fineness to improve material activity. Lee[12] mixed highly active slag in the raw materials to improve early strength and reaction speed and prepared a geopolymer that is equivalent to Portland cement in terms of strength at room temperature. Suwan[13] and Nath[14] mixed a small amount of ordinary Portland cement (OPC) in the raw material to prepare a high-strength geopolymer at room temperature. However, people pay little attention to the influence of alkali activator parameters on the property of materials at room temperature. 
The purpose of this study is to explore the influence of sodium silicate modulus and alkali activator dosage on geopolymer strength under an ambient-temperature curing condition and determine the optimum range of parameters. The influence of the inner source of the alkali activator on the mechanical performance of the material is also investigated by studying the microstructure of fly ash geopolymer reaction products.

\section{Experimental Investigation}

\subsection{Materials}

Fly ash with a density of $2.12 \mathrm{~g} / \mathrm{cm} 3$ and fineness of $10.8 \%$ was obtained from Fuxin Power Plant in China. A combination of sodium hydroxide $(\mathrm{NaOH})$ and sodium silicate $\left(\mathrm{Na}_{2} \mathrm{SiO}_{3}\right)$ was utilized as the alkaline activator in this study. Commercially available sodium hydroxide $(\mathrm{NaOH})$ with purity higher than $96 \%$ was used. Commercially available industrial-grade sodium silicate $\left(\mathrm{Na}_{2} \mathrm{SiO}_{3}\right)$ with $8.97 \% \mathrm{Na}_{2} \mathrm{O}, 29.16 \% \mathrm{SiO}_{2}$, and $61.87 \%$ water was also utilized. The required modulus was obtained by adding $\mathrm{NaOH}$ during the test. OPC with a grade of 42.5 conforming to the Chinese standard GB175-2007 was applied in the test. The chemical compositions and loss of ignition of materials are presented in Table 1. ISO standard sand was used as fine aggregate in the mortar test.

Table 1. Chemical Compositions (Wt. \%) of Materials

\begin{tabular}{|c|c|c|c|}
\hline $\begin{array}{c}\text { Compositi } \\
\text { on } \\
\end{array}$ & $\begin{array}{l}\text { Fly } \\
\text { ash }\end{array}$ & Slag & $\begin{array}{l}\text { Cem } \\
\text { ent }\end{array}$ \\
\hline $\mathrm{SiO}_{2}$ & $\begin{array}{l}53.7 \\
5\end{array}$ & 33.16 & 22.56 \\
\hline $\mathrm{Al}_{2} \mathrm{O}_{3}$ & $\begin{array}{l}29.3 \\
7\end{array}$ & 15.33 & 4.64 \\
\hline $\mathrm{CaO}$ & 3.68 & 37.15 & 61.28 \\
\hline $\mathrm{Fe}_{2} \mathrm{O}_{3}$ & 5.64 & 1.36 & 2.35 \\
\hline $\mathrm{MgO}$ & 1.08 & 9.07 & 2.04 \\
\hline $\mathrm{Na}_{2} \mathrm{O}$ & - & 0.36 & 0.6 \\
\hline $\mathrm{K}_{2} \mathrm{O}$ & 0.68 & 0.39 & 0.75 \\
\hline $\mathrm{SO}_{3}$ & 1.29 & 1.27 & 2.83 \\
\hline LOSS & 3.58 & 0.91 & 2.01 \\
\hline
\end{tabular}

\subsection{Test Plan}

Based on previous research, high-strength geopolymer was prepared with fly ash as a raw material by mixing $25 \%$ slag and $15 \%$ cement at ambient temperature. To study the influence of alkali dosage and sodium silicate modulus on the strength of geopolymers at ambient temperatures, the strength of geopolymer was measured at a water-binder ratio of 0.4 . The cement content was $15 \%$, the slag content was $25 \%$, the sodium silicate moduli were $1.0,1.2,1.4,1.6,1.8$, and 2.0 , and the alkali dosage was from $4 \%$ to $9 \%$ (the alkali dosage was represent by quality percentage of total $\mathrm{Na}_{2} \mathrm{O}$ in alkaline activator to fly ash).

To analyze the microstructure properties of fly ash geopolymer and study the influence of the inner source of alkali dosage and sodium silicate modulus on their performance, representative samples were selected for microstructure analysis. The activator parameters of the samples are shown in Table 2. 
Table 2. Activator Parameters of Samples for Microstructure Analysis

\begin{tabular}{ccc}
\hline Sample & $\begin{array}{c}\text { Dosage of } \\
\text { alkali } \\
\text { (Wt. \%) }\end{array}$ & $\begin{array}{c}\text { Sodium silicate } \\
\text { modulus }\end{array}$ \\
\hline WG1 & 8 & 1.6 \\
WG2 & 4 & 1.6 \\
WG3 & 8 & 2.0 \\
\hline
\end{tabular}

\subsection{Test Method}

In reference to the fly ash geopolymer strength test indicated in Method of Testing Cements - Determination of Strength (GB/T17671-1999), geopolymer mortar samples were prepared as follows. The test materials, which were in accordance with the preliminary mix proportion design, were mixed fully in a cement mortar mixer before casting in $40 \mathrm{~mm} \times 40 \mathrm{~mm} \times 160 \mathrm{~mm}$ steel molds. The samples were subjected to vibration to remove air bubbles. Thereafter, the samples were demolded and stored in a standard curing room at $20 \pm 2{ }^{\circ} \mathrm{C}$ and with more than $95 \%$ relative humidity until the age of $28 \mathrm{~d}$. Compressive strength tests were then performed.

Scanning electron microscopy (SEM; FEI Quanta TM250) was utilized to observe the microstructures of the fly ash geopolymer. The X-ray diffraction (XRD) patterns of the samples were measured with a D8 ADVANCE Bruker AXS X-ray diffractometer $(40 \mathrm{kV}$, $30 \mathrm{~mA}, \mathrm{Cu}-\mathrm{K} \alpha$ ). The pore structure of the fly ash geopolymer was measured through mercury porosimetry (Autopore IV9510). The microstructure experiment sample was used as the paste.

\section{Results and Discussion}

\subsection{Influence of Alkali Dosage on Strength}

The development in the strength of the geopolymer material is shown in Figure 1 under the conditions of different moduli of sodium silicate, and with the dosage of alkali increasing from $4 \%$ to $9 \%$.

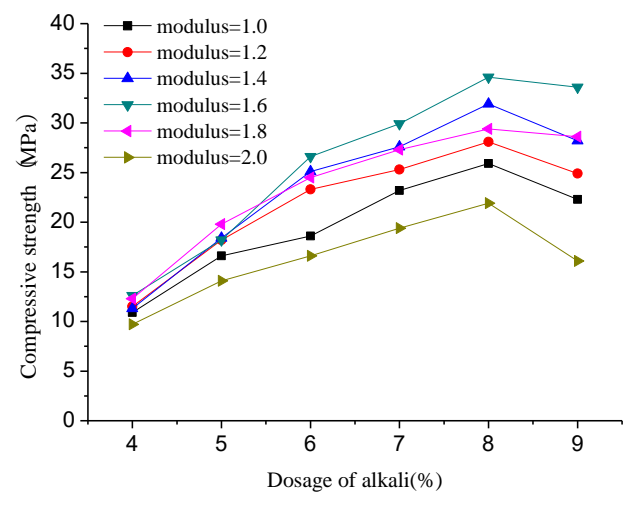

(a) 3 d age

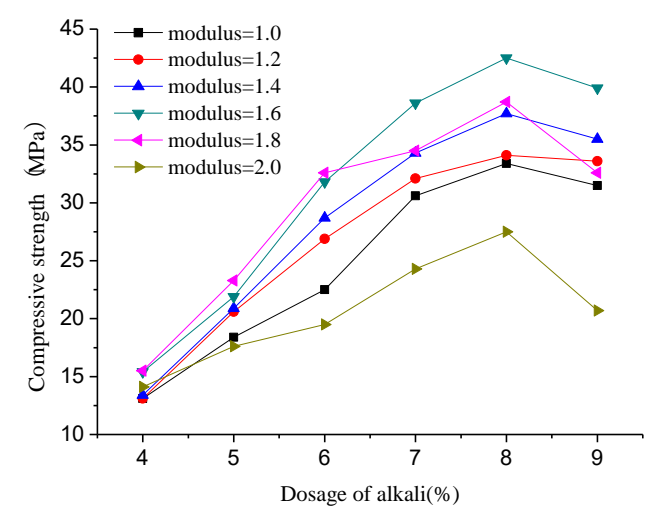

(b) $7 \mathrm{~d}$ age 


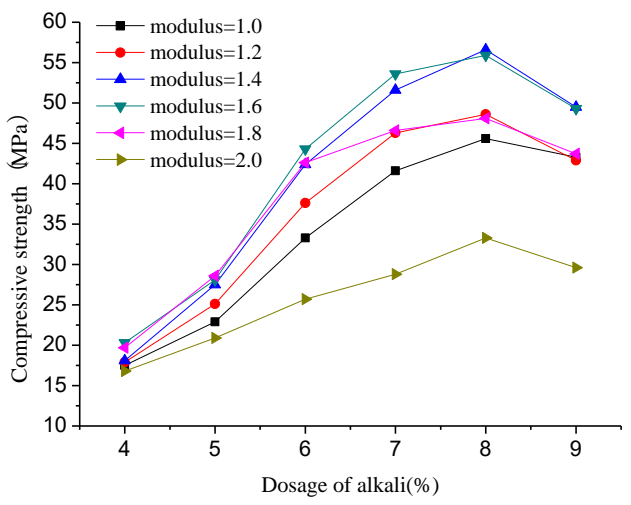

(c) $28 \mathrm{~d}$ age

\section{Figure 1. Influence of Alkali Dosage on Compressive Strength}

Figure 1 shows that the strength of the geopolymer with different ages decreases with the decrease in alkali dosage. However, as the alkali dosage gradually increases, the strength of the geopolymer presents an obvious increase. When the alkali dosage reaches $7 \%$ to $8 \%$, the strength of the samples with different ages is high. When the alkali dosage is $8 \%$, strength reaches the maximum. Thereafter, strength decreases as the alkali dosage increases.

When the alkali dosage and activator concentration are low, the alkali activation force is insufficient, and the glass shell dissolved on the surface of fly ash particles is limited. The active ingredients of silicon and aluminum inside are not released. Thus, the polymerization degree of the product in geopolymerization is low, resulting in the structure being not dense enough after material hardening. However, when the dosage of alkali is too high, excessive $\mathrm{Na}+$ is adsorbed on the surface of fly ash particles and hinders the further formation of a 3D network structure in the late stage of geopolymerization. Thus, the compressive strength of the material decreases. At the same time, the condensation rate of the mixture significantly and rapidly increases. The liquidity of the mixture mortar is reduced significantly when the dosage of alkali is too high. This condition leads to a decrease in strength because of difficult pouring of the mixture, excessive pores, and poor compactness of the sample.

\subsection{Influence of Sodium Silicate Modulus on Strength}

By reorganizing the test data of the influence of alkali dosage on the geopolymer, the rule of geopolymer strength can be obtained when the sodium silicate modulus changes from 1.0 to 2.0 in the conditions of different dosages of alkali. The results are shown in Figure 2.

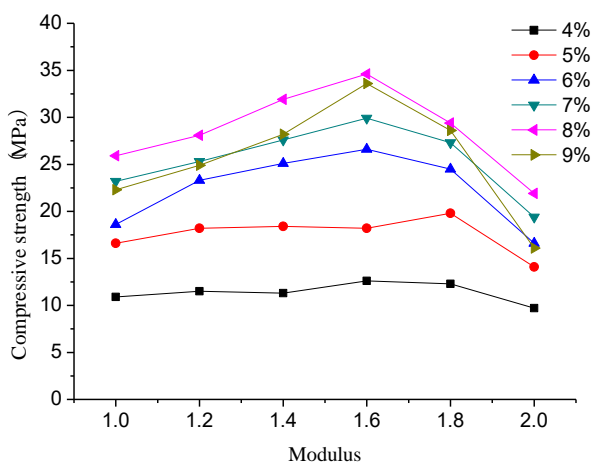

(a) 3 d age

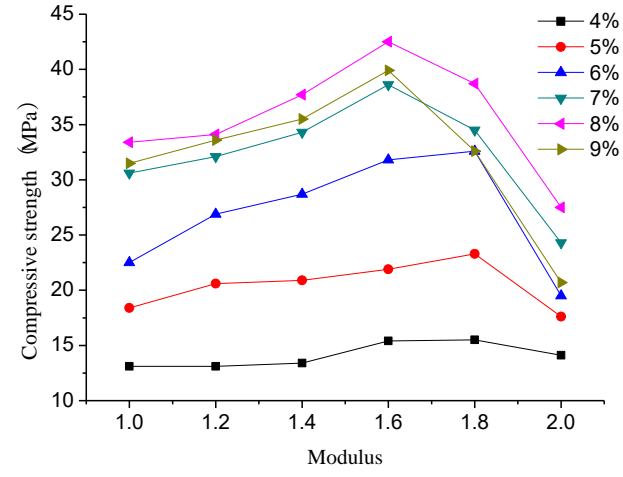

(b) $7 \mathrm{~d}$ age 


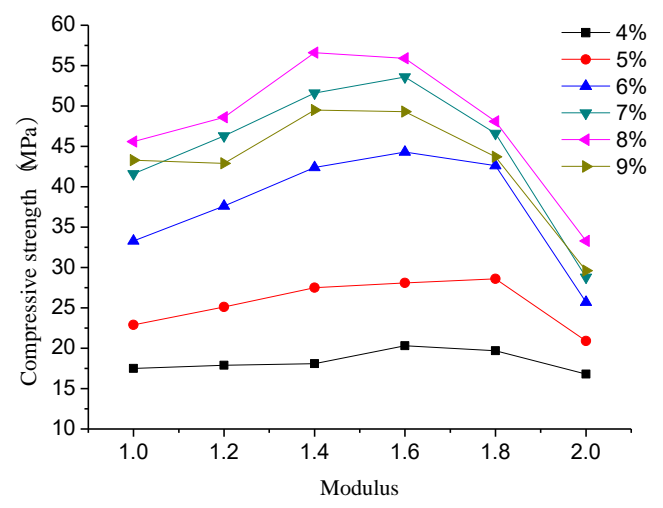

(c) $28 \mathrm{~d}$ age

\section{Figure 2. Influence of Sodium Silicate Modulus on Compressive Strength}

Figure 2 shows that strength with different ages increases initially and then decreases as the sodium silicate modulus gradually increases. Most of the samples gain maximum strength when the sodium silicate modulus is 1.4 to 1.6 . Strength decreases significantly when the sodium silicate modulus is 1.8 or 2.0. In conclusion, the modulus range of 1.4 to 1.6 is good for strength development of geopolymers.

With the increment in modulus, the ratio of $\mathrm{Si}-\mathrm{Al}$ participating in the reaction is high. The ratio of $\mathrm{Si}-\mathrm{O}-\mathrm{Si}$ with large bond energy in reaction products increases gradually. Therefore, the mechanical properties of the geopolymer improve significantly. However, when the sodium silicate modulus is excessively high, the mixture becomes sticky and strength decreases because the mixture cannot be vibrated easily and compactly; hence, many internal defects emerge after material hardening. By contrast, with the increment in modulus, high-silicate polymers in the reaction product increase remarkably after dissolving the fly ash. The contribution of high-silicate polymers on material strength is far less than that of low-silicate polymers. As a result, the strength of the material decreases significantly.

\subsection{Analysis of Geopolymer Microstructure}

The samples were observed through SEM, and the observation results after magnification by 1,000 times are shown in Figures 3 to 5 .

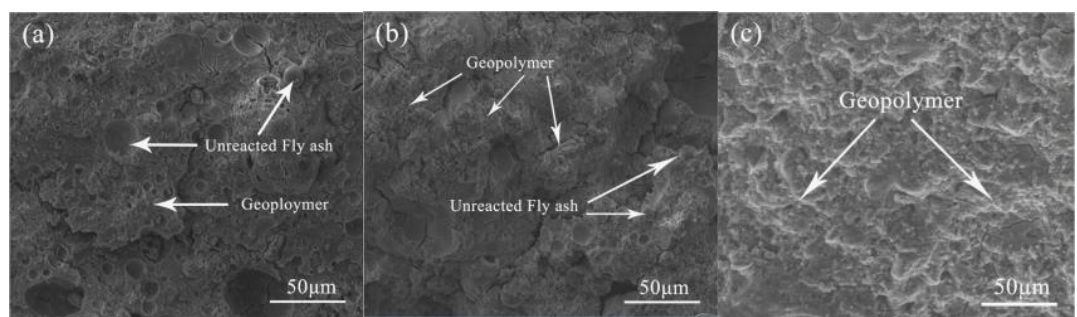

Figure 3. Microstructure of WG1: (a) $3 \mathrm{~d}$ Age, (b) $7 \mathrm{~d}$ Age and (c) $28 \mathrm{~d}$ Age 


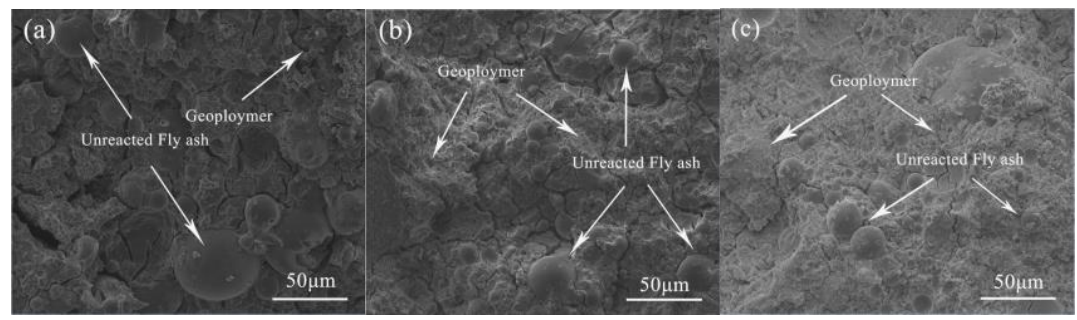

Figure 4. Microstructure of WG2: (a) $3 \mathrm{~d}$ Age, (b) $7 \mathrm{~d}$ Age and (c) $28 \mathrm{~d}$ Age

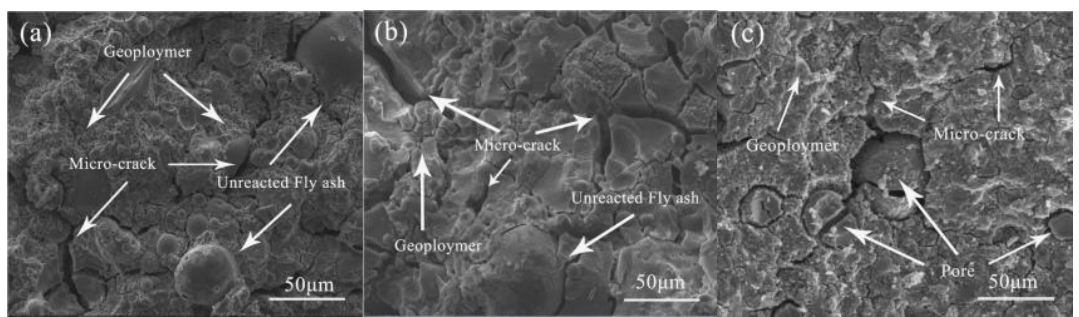

Figure 5. Microstructure of WG3: (a) $3 \mathrm{~d}$ Age, (b) $7 \mathrm{~d}$ Age and (c) $28 \mathrm{~d}$ Age

Figure 3 shows that many chemical network-like products are generated in WG1 at $3 \mathrm{~d}$ age. However, the connection extent is insufficient. A large amount of fly ash particles do not react. When the sample reaches $7 \mathrm{~d}$ age, the products are generated increasingly and begin to come into contact with one another. The structure then becomes dense. When the sample reaches $28 \mathrm{~d}$ age, few unreacted fly ash particles exist. The degree of the generated 3D network structure is high.

Figure 4 shows that the structure of the reaction product in WG2 at 3 and $7 \mathrm{~d}$ of age is relatively loose. Some unreacted fly ash particles exist. Even up to 28 day age, a large amount of unreacted fly ash particles still exist. This condition shows that the reaction is incomplete because of small alkali dosage. At same time, the reaction product attaches to the surface of fly ash particles, which hinders the further reaction of the active material inside. As a result, the 3D network structure of the material is not dense enough.

Figure 5 shows that the surface of fly ash particles of WG3 at $3 \mathrm{~d}$ age is corroded by the alkali activator. However, the reaction product appears to be smaller than that of the other samples. The structure is relatively looser, more cracks and pores exist, and the density is worse than that of the other samples. When the sample reaches $7 \mathrm{~d}$ age, a large amount of fly ash particles are involved in the reaction. However, the phenomena of being loose, not dense, and having too much cracks and pores of the reaction product are not transformed. When the sample reaches $28 \mathrm{~d}$ age, few unreacted fly ash particles are observed. However, overall, the density of the reaction product of the sample is worse than that of WG1. The number of cracks and pores is greater than that in the other samples.

The results of SEM analysis in Figures 3 to 5 indicate that when the dosage of alkali is $8 \%$ and the modulus of sodium silicate is 1.6 , the microstructure of the material is the densest. Thus, the geopolymerization is the fullest.

The XRD results of the samples at different ages are shown in Figure 6. 


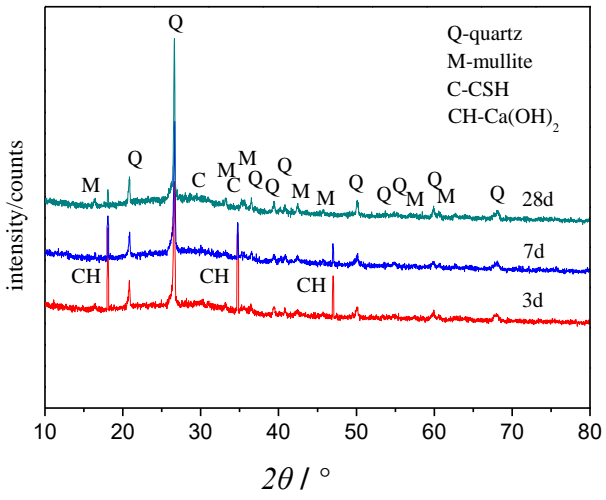

(a) WG1

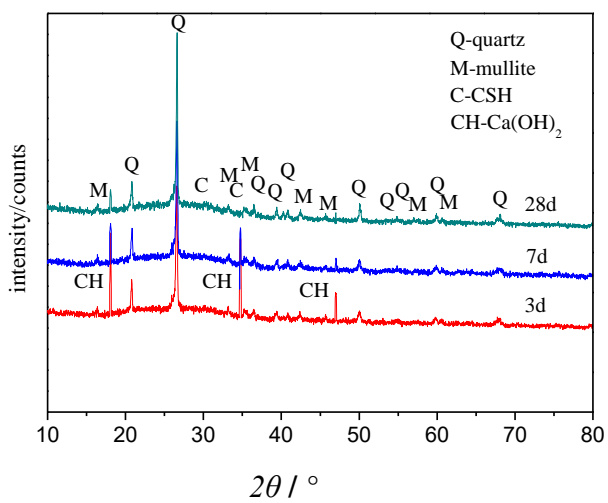

(b) WG2

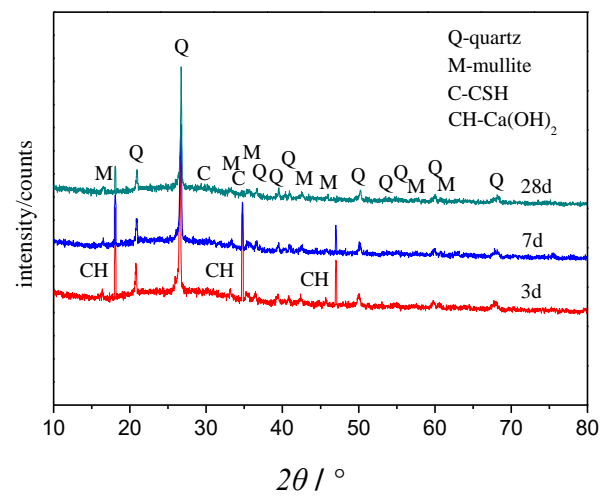

(c) WG3

Figure 6. XRD Results of the Geopolymer Sample

The XRD results of the three samples are basically identical. However, the height of the diffraction peaks differs. This height changes with the variation of the activator parameters and curing age. A variation in the alkali dosage and sodium silicate modulus of the activator exerts no effect on the phase composition of the geopolymer reaction product but can influence the amount of the product.

In the XRD diffraction experiment results of the reaction product, a "bulge" is uplifted at $2 \theta$ angle from $25^{\circ}$ to $35^{\circ}$ region. Moreover, with the increase in the dosage of alkali and the extension of curing age, the "bulge" increases obviously. This result shows that a large amount of amorphous materials are generated. With the increase in the dosage of alkali, the reaction products also increase.

The diffraction peak of $\mathrm{Ca}(\mathrm{OH})_{2}$ can be seen clearly in the early XRD results of the three samples. The peak is the hydrated reaction product of slag and cement. However, as the age increases, the diffraction peak of $\mathrm{Ca}(\mathrm{OH})_{2}$ decreases obviously and then almost disappears at the age of $28 \mathrm{~d}$. This result illustrates that $\mathrm{Ca}(\mathrm{OH})_{2}$ is also involved in the alkali activating reaction on the fly ash particles and is consumed in the formation of the geopolymer.

The MIP results of the fly ash geopolymer samples are shown in Figure 7 and Table 3. As shown in Figure 7, the most probable pore diameters of each sample are reduced and the porosity declines at 7 day age compared with that in the MIP results at $3 \mathrm{~d}$ age. The trend is more obvious at $28 \mathrm{~d}$ age. This result shows that the reaction products increase continuously and can make the material highly compact with the extension of curing age for each sample. 


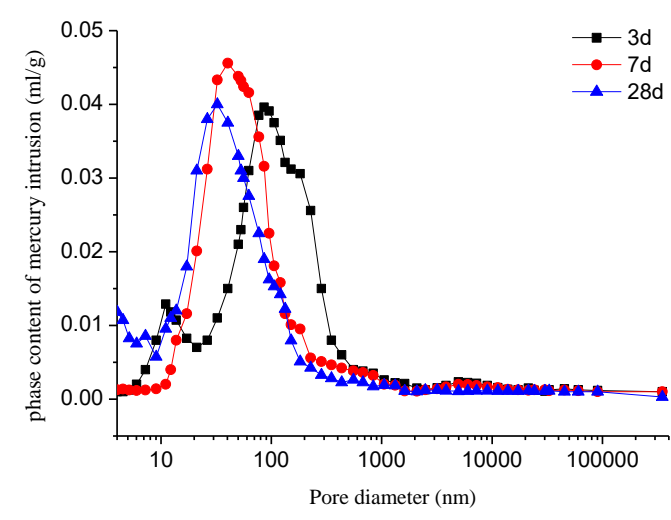

(a) WG1

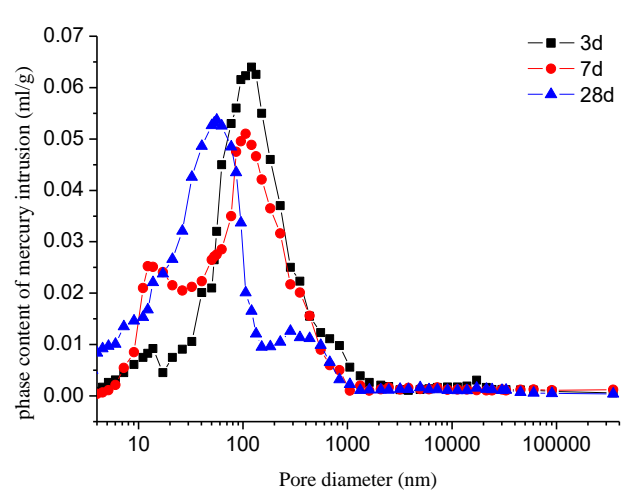

(b) WG2

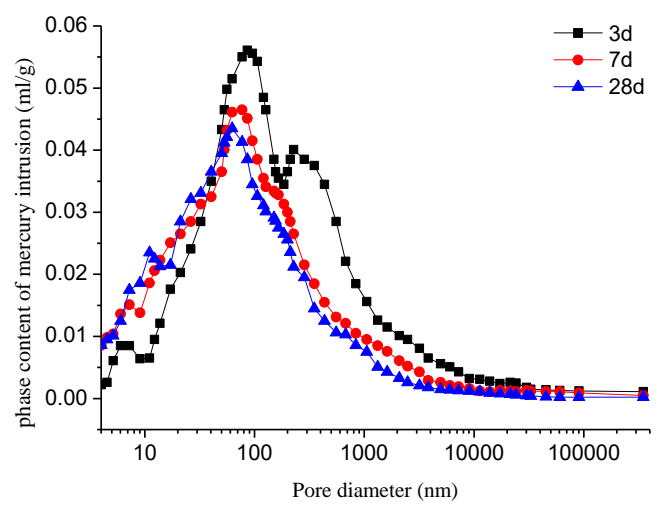

(c) WG3

Figure 7. Curve of Pore Diameter-Phase Content of Mercury Intrusion of the Samples

Table 3. Basic Parameters of the Pore Structure of the Samples

\begin{tabular}{ccccc}
\hline \multirow{2}{*}{ Sample } & Age & $\begin{array}{c}\text { Average } \\
\text { pore diameter } \\
(\mathbf{n m})\end{array}$ & $\begin{array}{c}\text { Most } \\
\text { probable pore } \\
\text { diameter } \\
(\mathbf{n m})\end{array}$ & $\begin{array}{c}\text { Porosity } \\
(\boldsymbol{\%})\end{array}$ \\
\hline \multirow{3}{*}{ WG1 } & 3d & 65.3 & 86.1 & 9.312 \\
& $7 \mathrm{~d}$ & 38.6 & 43.3 & 8.264 \\
& 28d & 26.4 & 32.6 & 6.737 \\
\cline { 2 - 5 } WG2 & 3d & 58.1 & 133.4 & 11.464 \\
& 7d & 51.5 & 106.5 & 10.756 \\
& 28d & 46.8 & 56.2 & 7.565 \\
\cline { 2 - 5 } WG3 & 3d & 86.6 & 88.3 & 15.371 \\
& 28d & 77.1 & 79.4 & 15.178 \\
\end{tabular}

As shown in Table 3, the porosity of WG1 is at the minimum, and the most probable pore diameter is also at the minimum. This result shows that the alkali dosage and sodium silicate modulus are within the optimal range. The degree of reaction of WG2 is not better than that of WG1 because of the decrease in alkali dosage. Thus, the porosity and most 
probable pore diameter increase. The porosity and most probable pore diameter of WG3 are larger than those of WG1, and the change in porosity of WG3 is not greater than that in the other samples with the extension of curing age.

Pore size distribution has a direct influence on the properties of materials. Different pore sizes affect the properties of materials differently. The famous material expert of China, Zhong-wei $\mathrm{Wu}$, reported that pores can be divided into four types according to their size and degree of influence on the properties of concrete. These four types are harmless pores (pore size $<20 \mathrm{~nm}$ ), less harmful pores $(20-50 \mathrm{~nm})$, harmful pores $(50-200 \mathrm{~nm})$, and very harmful pores $(>200 \mathrm{~nm})$. In accordance with the MIP results of this study, the corresponding situations in the pore size distribution of the samples at different ages were obtained and then drawn in the form of histograms, as shown in Figure 8 .

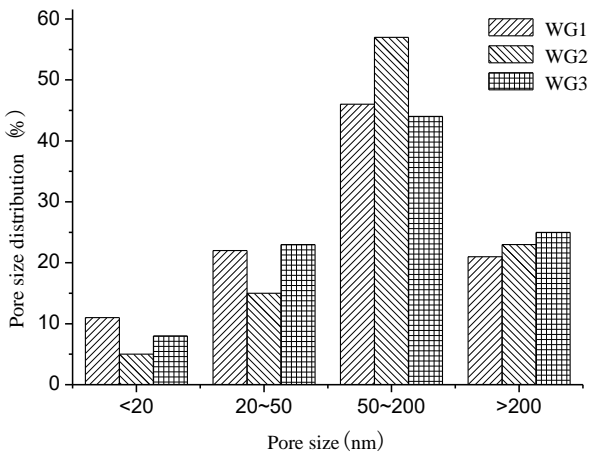

(a) 3 d age

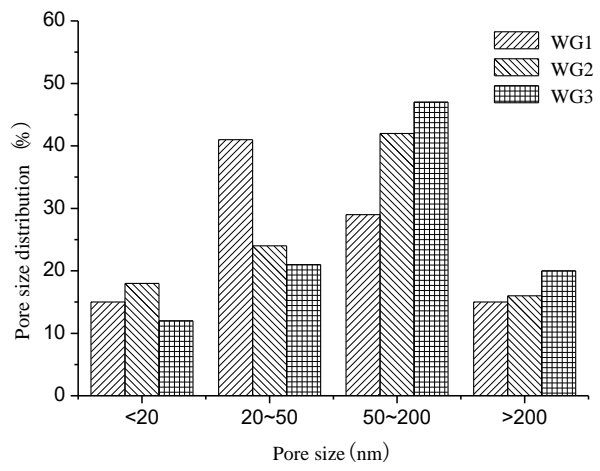

(b) 7 d age

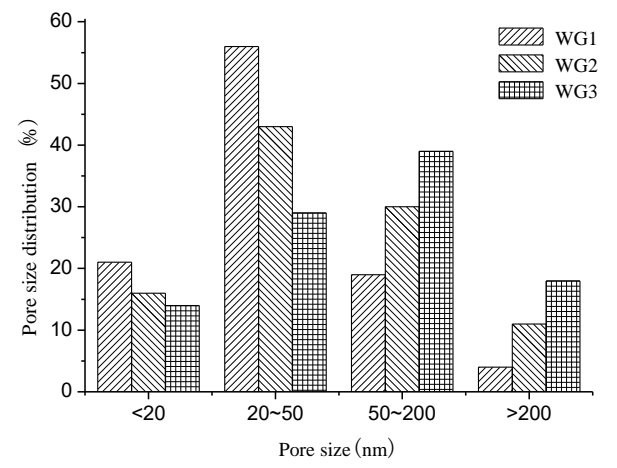

(c) $28 \mathrm{~d}$ age

\section{Figure 8. Pore Size Distribution Histogram of the Samples}

The harmful pores maintain a large proportion in each sample at $3 \mathrm{~d}$ age, and the proportion of harmless pores increases in WG1 at $7 \mathrm{~d}$ age. Meanwhile, harmful pores still dominate in WG2 and WG3. When the samples reach $28 \mathrm{~d}$ age, the harmful pores in WG2 are dramatically reduced, and the harmless pores already maintain a large proportion. This result shows that with a small dosage of alkali, the reaction of fly ash is slow. The compactness of the material improves with the extension of curing age, especially after $28 \mathrm{~d}$. Harmful pores still account for the largest proportion in WG3 at different ages. This result suggests that a high sodium silicate modulus exerts an adverse effect on the formation of geopolymer. 


\section{Conclusions}

Geopolymers with high strength can be produced at ambient temperatures after adding slag and cement. Alkali dosage of $7 \%$ to $8 \%$ and sodium silicate modulus of 1.4 to 1.6 are the optimal ranges that can increase the strength of geopolymers. SEM and MIP analyses indicate that when the dosage of alkali is $8 \%$ and the sodium silicate modulus is 1.6 , the microstructure of the material is relatively very compact, the porosity of the samples is low, and the most probable pore diameter is at the minimum. Less harmful pores maintain a large proportion of the pore size distribution. With prolonged curing age, the trend becomes highly significant. The XRD results show that changes in the dosage of alkali and sodium silicate modulus exert little effect on the phase composition of the product but can influence the quantity of the product.

\section{Acknowledgments}

This work is supported by Foundation of Liaoning Educational Committee (No. L2014137), National Natural Science Foundation of China (No. U1261122), National Undergraduate Training Program for Innovation and Entrepreneurship (201510147014).

\section{References}

[1] J. Davidovits, "Geopolymers: Inorganic polymeric new materials", Journal of Thermal Analysis, vol. 37, no. 8, (1991), pp.1633-1639.

[2] B. C. McLellan, R. P. Williams, J. Lay, A. van Riessen and G. D. Corder, "Costs and carbon emissions for geopolymer pastes in comparison to ordinary portland cement",Journal of Cleaner Production, vol. 19, no. 9-10, (2011), pp. 1080-1090.

[3] C. J. Shi, A. Fernández-Jiménez and A. Palomo, "New cements for the 21 st century: the pursuit of an alternative to Portland cement", Cement and Concrete Research, vol. 41, no. 7, (2011), pp. 750-763.

[4] P. Duxson, A. Fernández-Jiménez, J. L. Provis, G. C. Lukey, A. Palomo and J. S. J. van Deventer, "Geopolymer technology: the current state of the art", Journal of Materials Science, vol. 42, no. 9, (2007), pp. 2917-2933.

[5] H. Li and D. L. XU, "The Future Resources for Eco-building Materials: II. Fly Ash and Coal Waste", Journal of Wuhan University of Technolotgy-Mater, vol. 24, no. 4, (2009), pp. 667-672.

[6] J. C. Swanepoel, C. A. Strydom, "Utilisation of fly ash in a geopolymeric material", Applied Geochemistry, vol. 17, no. 8, (2002), pp. 1143-1148.

[7] G. Görhan and G. Kürklü, "The influence of the $\mathrm{NaOH}$ solution on the properties of the fly ash-based geopolymer mortar cured at different temperatures", Composites: Part B, vol. 58, (2014), pp. 371-377.

[8] T. Bakharev, "Geopolymeric materials prepared using class F fly ash and elevated temperature curing", Cement and Concrete Research, vol. 35, no. 6, (2005), pp. 1224-1232.

[9] G. Kovalchuk, A. Fernández-Jiménez and A. Palomob, "Alkali-activated fly ash: effect of thermal curing conditions on mechanical and microstructural development-Part II", Fuel, vol. 86, no. 3, (2007), pp. 315-322.

[10] K. Somna, C. Jaturapitakkul, P. Kajitvichyanukul and P. Chindaprasirt, "NaOH-activated ground fly ash geopolymer cured at ambient temperature", Fuel, vol. 90, no. 6, (2011), pp. 2118-2124.

[11] J. Temuujin, R. P. Williams and A. van Riessen, "Effect of mechanical activation of fly ash on the properties of geopolymer cured at ambient temperature", Journal of Materials Processing Technology, vol. 209, no. 12-13, (2009), pp. 5276-5280.

[12] N. K. Lee and H. K. Lee, "Setting and mechanical properties of alkali-activated fly ash/slag concrete manufactured at room temperature", Construction and Building Materials, vol. 47, (2013), pp.1201-1209.

[13] T. Suwan and M. Fan, "Influence of OPC replacement and manufacturing procedures on the properties of self-cured geopolymer", Construction and Building Materials, vol. 73, (2014), pp.551-561.

[14] P. Nath and P. K. Sarker, "Use of OPC to improve setting and early strength properties of low calcium fly ash geopolymer concrete cured at room temperature", Cement \& Concrete Composites, Vvol. 55, (2015), pp. 205-214. 


\section{Authors}

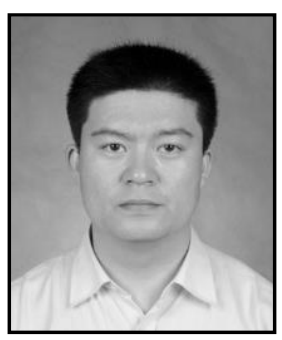

Qingwei Sun, he received his B.S. and M.S. Degree in Shenyang Jianzhu University and Liaoning Technical University, respectively. $\mathrm{He}$ is currently a Ph.D. candidate at Tianjin University. Since 2013 he has been an associate professor at College of Civil Engineering and Architecture, Liaoning Technical University. His research fields include materials science, civil Engineering and control engineering. 
International Journal of Control and Automation

Vol. 9, No. 9 (2016) 